\title{
PENDEKATAN KEPEMIMPINAN TRANSFORMASIONAL KEPALA SEKOLAH BERBASIS NILAI-NILAI BUDAYA, HUMANISTIK, DAN NASIONALISME DALAM PENGUATAN PENDIDIKAN KARAKTER
}

\author{
Yulius Rustan Effendi \\ Universitas Negeri Malang \\ email: fenalm.21@gmail.com
}

\begin{abstract}
Abstrak: Penelitian ini bertujuan untuk mendekripsikan alasan diterapkan pendekatan budaya, humanistik, dan nasionalisme oleh kepala sekolah dalam mendukung perilaku kepemimpinan transformasional. Selain itu, penelitian ini bertujuan untuk mendalami langkah-langkah peran kepemimpinan transformasional kepala sekolah berbasis tiga bentuk pendekatan dalam pelaksanaan program penguatan pendidikan karakter. Penelitian ini menggunakan pendekatan kualitatif dengan desain studi kasus. Pengumpulan data dilakukan melalui wawancara mendalam, observasi partisipan, dan studi dokumentasi. Analisis data menggunakan teknik analisis analitik yang dimodifikasi. Validitas data berdasarkan tingkat kredibilitas, transferabilitas, dependabilitas, dan konfirmabilitas. Temuan penelitian menjelaskan bahwa lingkungan sekolah yang kuat dipengaruhi oleh budaya dan tradisi, keunggulan pribadi pemimpin dan dorongan untuk menghidupkan kembali spiritualitas humanis figur inspiratif, serta citra yayasan sekolah yang dikelola oleh satuan Militer, Kodam V-Brawijaya Malang, menjadi alasan dasar kepala sekolah menerapkan pendekatan budaya, humanistik, dan nasionalisme. Selain itu, langkah-langkah peran kepemimpinan transformasional kepala sekolah berbasis pendekatan budaya, humanistik, dan nasionalisme berdampak efektif dalam mengoptimalkan pelaksanaan penguatan pendidikan karakter di sekolah.
\end{abstract}

Kata kunci: kepemimpinan transformasional, pendekatan kepala sekolah, penguatan pendidikan karakter

\section{TRANSFORMATIONAL LEADERSHIP APPROACH OF PRINCIPAL BASED ON CULTURAL VALUES, HUMANISTICS, AND NATIONALISM IN STRENGTHENING CHARACTER EDUCATION}

\begin{abstract}
This study aims to describe the reasons for applying the cultural, humanistic, and nationalism approaches by principals in supporting transformational leadership behavior. In addition, to explore the steps of the principal's transformational leadership role based on three forms of approach in the implementation of character education strengthening programs. This study used a qualitative approach, case study design. Data collection through in-depth interviews, participant observation, and learn documentation. Data analysis used a modified analytic analysis method. The level of credibility, transferability, dependability, and confirmability examines the validity of the data. The research findings explain that culture or tradition greatly influences the school environment, personal excellence, and encouragement to revive the humanistic spiritual inspirational figure, as well as the image of the school foundation managed by the Military unit, Kodam V-Brawijaya, being the basic reason that inspires the principal to use a cultural, humanistic approach, and nationalism. Besides that the steps of the principal's transformational leadership role based on cultural, humanistic, and nationalism approaches have an effective effect in optimizing the implementation of character education strengthening in schools.
\end{abstract}

Keywords: transformational leadership, principal approach, character education strengthening

\section{PENDAHULUAN}

Kemajuan di era global dialami dalam bentuk perubahan cara berpikir, berkomu- nikasi, dan bertindak (Cook, et al., 2016). Perubahan yang terjadi memperkuat otonomi individu dalam membangun identitas dan moralitas (Veugelers, 2007). Di sisi lain, 
kemajuan menghadirkan fakta dilematis yang menghilangkan kesadaran kritis manusia (Lovvorn \& Chen, 2011). Kesadaran kritis melemah, karena antara kemajuan dan otonomi moral pribadi tidak berjalan seiring, sehingga menyebabkan dehumanisasi, yang berdampak pada konflik moral. Di tingkat remaja Sekolah Menengah Pertama (SMP) di Indonesia, fakta penyimpangan moral ditemukan dalam beberapa sikap amoral, seperti; intoleran, perkelahian antara pelajar, penggunaan narkoba, pergaulan bebas, mencontek, mencuri, tidak disiplin, berpakaian tidak sopan, nilai-nilai etika dan tata krama yang baik dalam komunikasi memudar, kekerasan dan anarkisme oleh kelompok sebaya, etos kerja tidak berharga, tidak menghargai diri (seks bebas, bunuh diri, pemerasan), memudarnya nilai-nilai nasionalisme dan patriotisme (Koesoema, 2010; Endah, 2012; The Ministry of Education and Culture, 2016).

Menyikapi masalah penyimpangan moral di kalangan siswa ini, Kementerian Pendidikan Nasional Indonesia, melakukan revitalisasi kebijakan pendidikan melalui program Penguatan Pendidikan Karakter (PPK). Revitalisasi kebijakan ini dituangkan dalam Peraturan Pemerintah Republik Indonesia (PP) Nomor 87 Tahun 2017 tentang Penguatan Pendidikan Karakter (PPK), Bab I, Pasal 1 yang menegaskan bahwa program penguatan pendidikan karakter merupakan aktivitas pedagogik yang menyatukan hati, rasa, pikiran, dan tubuh serta dijalankan melalui kerja sama antara komponen internal sekolah, orang tua, dan masyarakat seiringdengan dorongan membentuk mental melalui Gerakan Nasional Revolusi Mental.

Peraturan Pemerintah tersebut wajib diimplementasikan di tingkat Sekolah Dasar, Sekolah Menengah Pertama, dan Sekolah menengah Atas, melalui koordinasi intensif dengan seluruh komponen sekolah, termasuk peran kepala sekolah. Meskipun program penguatan pendidikan karakter telah berjalan sejak tahun 2017, namun di tingkat sekolah belum optimal dilaksanakan (Koesoema, 2015). Kondisi ini disebabkan oleh tiga kelemahan utama kepemimpinan kepala sekolah. Pertama, kepala sekolah belum menemukan pendekatan yang dapat mentransformasikan nilai-nilai karakter yang sesuai dengan budaya setempat. Dalam konteks ini, Sagala (2008) dan Daryanto (2015) menjelaskan beberapa indikator kelemahan kepala sekolah, yaitu: (1) memberi pengaruh ideal yang tidak selaras dengan tata perilaku budaya setempat, menyebabkan rendahnya kepercayaan, simpati, dan loyalitas pengikut terhadap pemimpin; (2) motivasi inspiratif yang tidak didukung oleh relasi individu, melalui tata cara budaya setempat, menyebabkan pengikut tidak terdorong untuk bekerja melampaui apa yang telah ditargetkan bersama; (3) stimulasi intelektual yang terkesan mendikte pengikut dan menilai pengikut sebagai pribadi yang perlu didorong, dinilai tidak etis secara budaya, dan akibatnya keinginan untuk memecahkan masalah lama dengan cara baru tidak berjalan dan sebaliknya menimbulkan masalah baru; dan (4) kepedulian terhadap individu yang hanya dinilai sebagai bentuk tanggung jawab pemimpin, tanpa didasarkan pada kepedulian karakter individu yang berbudaya, tidak mendatangkan kesejahteraan bagi pengikut, bahkan menghilangkan simpati pengikut kepada pemimpin (Kleden, 1987; Koesoema, 2015).

Kedua, kepala sekolah belum menemukan pendekatan untuk mentransformasikan nilai-nilai karakter yang bermakna memanusiakan manusia (Koesoema 2010; Lickona, 2012; Melé, 2016; Waddock, 2016). Beberapa indikator kelemahan kepala sekolah, yaitu: (1) berfokus pada diri pemimpin dengan mengagungkan diri dan 
kekuasaan, sehingga mengabaikan prinsip kesetaraan, kedewasaan, dan kepribadian pengikut; (2) pemimpin menjalankan kekuasaan atas pengikut, yang terpola sejak rezim Soeharto; (3) pemimpin dan pengikut tidak berada pada level yang sama dan masih ada hierarki yang membatasi, sehingga pengikut hanya menunggu perintah pemimpin (top-down); (4) pemimpin kurang memperhatikan perkembangan pribadi para pengikut atau kesejahteraan mereka; (5) kepala sekolah belum mampu mendesain pendidikan yang bermakna memanusiakan manusia yang berkarakter, sehingga tidak inovatif dalam menerapkan Kurikulum 2013; (5) penguatan pendidikan karakter masih belum mendapat posisi sentral dalam kurikulum sekolah, dan masih bersifat tempelan saja, sehingga menghambat pengembangan diri siswa; dan (6) nilai-nilai karakter tidak terintegrasi dalam pembelajaran, lingkungan sekolah tidak menjadi lingkungan pemberdayaan manusia yang berkarakter, kurang melibatkan orang tua dan masyarakat dalam mendukung pembentukan karakter siswa di sekolah.

Ketiga, kepala sekolah belum menemukan pendekatan untuk mentransformasikan nilai-nilai karakter yang berwawasan nasionalisme (Zamroni, 2011). Beberapa indikator kelemahan kepala sekolah, yaitu: (1) pengaruh ideal yang tidak didasarkan pada nilai-nilai nasionalisme dan patriotisme menyebabkan rendahnya kesadaran pengikut membangun karakter kebangsaan di lingkungan sekolah; (2) motivasi inspiratif yang mendorong pengikut bekerja melampaui target bersama, akan mengalami hambatan, jika motivasi yang diberikan masih memililiki muatan diskriminasi suku, agama, ras, dan budaya; (3) Stimulasi intelektual yang mendukung cara kerja yang kreatif dan inovatif tidak terlaksana, jika lingkungan sekolah belum terkondisi dengan kehidupan yang toleran, menghargai perbedaan, dan terbuka menerima semua warga sekolah tanpa ada perbedaan; dan (4) kepedulian terhadap individu yang dilandasi diskriminasi suku, agama, ras dan golongan. Jika kelemahan ini tidak segera diatasi, maka warga sekolah akan kehilangan kesadaran akan kecintaan pada bangsa dan negara.

Menanggapi kelemahan peran kepala sekolah, dalam terang penelitian terbaru, kami menemukan model kepemimpinan transformasional dengan pola pendekatan yang unik dan khusus, pada tiga sekolah yang diteliti, yaitu SMP Negeri yang berlokasi di luar pulau Jawa, tepatnya di pulau Flores Barat, Indonesia Timur, SMP Swasta Katolik dan SMP Swasta Nasional yang berada di Kota Malang, Jawa Timur. Ketiga kepala sekolah sama-sama menggunakan model kepemimpinan transformasional, dengan pola pendekatan yang berbeda.

Di SMP Negeri, Flores Barat - Indonesia Timur, yang dilatarbelakangi lingkungan sekolah yang masih memegang teguh nilai budaya dan tradisi, kepala sekolah cenderung menggunakan pola pendekatan budaya "lonto leok" masyarakat Manggarai. Di SMP Swasta Katolik, penerapan kepemimpinan transformasional kepala sekolah didasarkan pada pendekatan humanistik. Pendekatan ini diinspirasi oleh keunggulan diri (integritas, keutuhan, kesejatian diri) yang nampak dalam sikap terbuka, eksistensialitas pada pengalaman baru, kosistensi, fleksibilitas, kreatif, dan konstruktif) dan terdorong untuk menghidupkan kembali spiritualitas tokoh pendiri kongregasi kebiaraan yaitu "mencintai sesama manusia sebagai citra Allah", terinspirasi dari Alkitab: "So God created mankind in his own image, in the image of God he created them; male and female he created them" (Genesis 1:27 New International Version). 
Sedangkan di SMP Swasta Nasional, yang dilatarbelakangi oleh citra yayasan sekolah yang dikelola oleh satuan Militer, Kodam V-Brawijaya, Malang, maka kepala sekolah menggunakan pola pendekatan nasionalisme dalam semangat kebangsaan dan kebinekaan.

Berdasarkan pola pendekatan yang berbeda dalam penerapan kepemimpinan transformasional oleh tiga kepala sekolah, maka kontribusi penelitian kami adalah memosisikan dimensi pengajaran budaya "lonto leok" masyarakat Manggarai, dimensi humanistik yang bersumber dari keunggulan diri dan spiritualitas tokoh inspiratif, serta dimensi nasionalisme dalam semangat kebangsaan dan kebinekaan, sebagai pendekatan utama dalam mengoptimalkan pelaksanaan penguatan pendidikan karakter. Selain itu, penelitian ini dapat digunakan sebagai tawaran pendekatan kepemimpinan transformasional kepala sekolah dalam mengoptimalkan pelaksanaan program penguatan pendidikaan karakter. Dengan demikian, hasil penelitian ini dapat direkomendasi bagi para kepala sekolah di seluruh Indonesia, agar dalam mengoptimalkan pelaksanaan program penguatan pendidikan karakter, perlu menerapkan model kepemimpinan transformasional yang barbasis pada tiga pendekatanyang ditawarkan, karena terbukti efektif, sebagaimana yang telah dipraktikkan oleh ketiga kepala sekolah.

\section{METODE}

\section{Desain Penelitian}

Penelitian ini menggunakan desain penelitian kualitatif deskriptif-analitik, dengan tujuan untuk mengumpulkan data dan dideskripsikan dalam bentuk kata-kata tertulis atau lisan, disusun dalam kalimat ber- dasarkan wawancara dengan informan (Denzin \& Lincoln, 2000; Miles, Huberman \& Saldana, 2014). Kehadiran peneliti merupakan tolok ukur keberhasilan dalam membedah beberapa kasus. Peneliti bertindak, dengan bantuan orang lain, sebagai instrumen kunci dalam mengumpulkan data dari orang-orang yang terlibat aktif di dua sekolah yang diteliti (kepala sekolah, guru, staf, siswa, orang tua, komite sekolah, masyarakat, dan yayasan sekolah).

Teknik pengambilan sampel dalam penelitian ini adalah purposive sampling, yang diterapkan menggunakan teknik cerobong asap. Proses pengumpulan data, dimulai dari pengumpulan data yang luas, kemudian dipersempit untuk mendalami fokus penelitian. Selama periode waktu satu tahun enam bulan (2018 hingga Juni 2019), penelitian ini dilakukan di salah satu SMP Negeri di Flores Barat, Indonesia Timur, dan dua sekolah di Kota Malang, Jawa Timur, Indonesia Tengah, yaitu di salah satu SMP Swasta Katolik dan SMP Umum Nasional.

\section{Data dan Sumber Data}

Sumber data penelitian ini berasal dari data primer yang diperoleh dari informan kunci dalam bentuk kata-kata atau kata-kata verbal, dan dari data sekunder dalam bentuk dokumen, sebagai pelengkap data primer (Creswell, 2009; Yin, 2017). Pemilihan informan dilakukan dengan beberapa teknik: pertama, purposive sampling, memilih informan yang benar-benar menguasai informasi secara mendalam, andal sebagai sumber data yang valid. Sumber data yang digunakan dalam penelitian ini disajikan dalam Tabel 1 berikut. 
Tabel 1. Informan Data yang Digunakan sebagai Sumber Informasi

\begin{tabular}{|c|c|c|c|}
\hline No & Nama Sekolah & Informan & $\begin{array}{l}\text { Jumlah } \\
\text { Informan }\end{array}$ \\
\hline 01. & $\begin{array}{l}\text { SMP Negeri Flores Barat, } \\
\text { Indonesia Timur }\end{array}$ & $\begin{array}{l}\text { Kepala Sekolah, Guru, Staf, Siswa, Orang Tua, Komite } \\
\text { Sekolah, Alumni, Pengawas Sekolah, Aktivis Budaya }\end{array}$ & 25 \\
\hline \multirow[t]{2}{*}{02} & SMP Swasta Katolik & Kepala Sekolah, Guru, Staf, Siswa, Orang & \\
\hline & & $\begin{array}{l}\text { Tua, Komite Sekolah, Alumni, Pengawas Sekolah, } \\
\text { Yayasan Pengelola Sekolah }\end{array}$ & 25 \\
\hline \multirow[t]{2}{*}{03} & SMP Umum Nasional & $\begin{array}{l}\text { Kepala Sekolah, Guru, Staf, Siswa, Orang Tua, Komite } \\
\text { Sekolah, Alumni, Pengawas Sekolah, Yayasan Penge- } \\
\text { lola Sekolah }\end{array}$ & 25 \\
\hline & Total Jumlah Informan & - & 75 \\
\hline
\end{tabular}

Kedua, pengambilan sampel dengan teknik bola salju, yaitu mencari informasi secara terus-menerus dari satu informan ke informan lain, sehingga data yang diperoleh semakin lengkap dan mendalam, dan berhenti ketika data yang diperoleh dianggap telah jenuh. Terkait dengan peristiwa atau kegiatan di sekolah, pengamatan langsung diadakan (Miles, Huberman, \& Saldana, 2014).

\section{Teknik Analisis Data}

Teknik yang digunakan dalam analisis data, yaitu bekerja dengan data, melalui proses pencarian sistematis dan pengorganisasian karakter wawancara, catatan lapangan, dan bahan-bahan lain yang dikumpulkan oleh peneliti (Cresswell, 2009; Miles, Huberman, \& Saldana, 2014). Kegiatan analisis dilanjutkan dengan menganalisis data, menyusun, membagi menjadi beberapa unit, mensintesis, mencari pola, menemukan apa yang bermakna dan apa yang diteliti dan dilaporkan secara sistematis. Pada tahap ini, analisis data dilakukan dan digunakan sedemikian rupa untuk memperoleh kebenaran data yang digunakan untuk menjawab fokus penelitian ini. Kemudian data disajikan sehingga memungkinkan penarikan simpulan dan tindakan.

\section{Validitas Data}

Validitas data dalam penelitian ini menggunakan beberapa langkah. Pertama, ukuran kredibilitas (tingkat kepercayaan). Tujuan kredibilitas data untuk membuktikan kesesuaian data dengan fakta-fakta dalam penelitian. Untuk menetapkan validitas data, peneliti menggunakan teknik inspeksi berikut. (1) Memperluas keterlibatan, sehingga memungkinkan peningkatan tingkat kepercayaan pada data yang dikumpulkan. Dengan memperpanjang keterlibatan, akurasi informasi diperoleh, dan membangun kepercayaan pada subjek. Oleh karena itu, peneliti memperluas partisipasi yang terjadi di latar belakang penelitian. (2) Kegigihan pengamatan, berarti bahwa peneliti secara rinci mencari dan menemukan karakteristik dan elemen dalam situasi yang sangat relevan dengan masalah yang sedang dipelajari. (3) Triangulasi membantu pengecekan data dengan membandingkannya dengan sesuatu yang lain. Triangulasi yang digunakan yaitu triangulasi sumber, triangulasi metode, dan triangulasi teori.

\section{HASIL DAN PEMBAHASAN}

\section{Latar Belakang Pendekatan Kepala Se- kolah}

Optimalisasi penguatan pendidikan karakter di sekolah, dan kelemahan peran kepala sekolah menjadi masalah urgen yang perlu diatasi dalam lingkungan pendidikan di Indonesia (Sagala, 2008; Dar- 
yanto, 2015; Damayanti, 2017). Kelemahan peran kepala sekolah ini perlu ditampilkan ke permukaan, agar ditemukan langkah solutif sebuah perubahan. Perubahan terjadi sebagaimana yang dilakukanoleh tiga kepala sekolah, yang telah menerapkan model kepemimpinan transformasional dengan pola pendekatan yang berbeda.

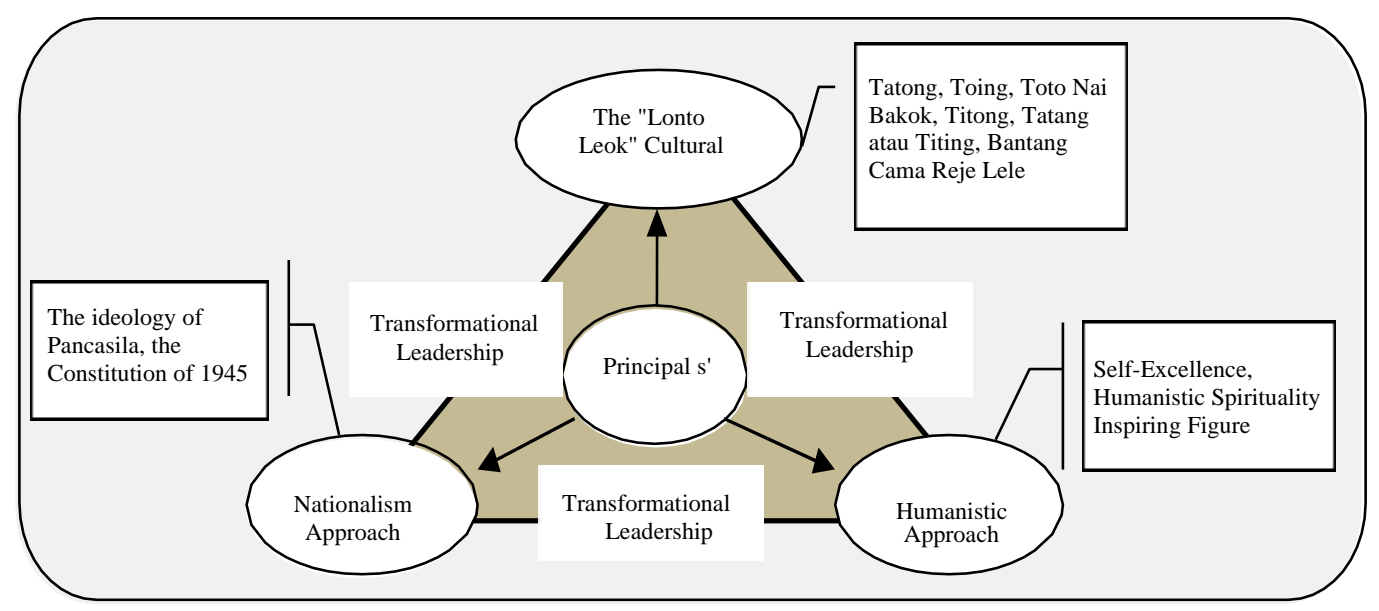

Gambar 1. Pendekatan Para Kepala Sekolah

Gambar 1 menjelaskan bahwa pola pendekatan ketiga kepala sekolah dilatarbelakangi oleh: (1) kondisi dan latar belakang sekolah (tujuan sekolah didirikan, sumber daya, dan lingkungan budaya); (2) keunggulan diri pemimpin dan inspirasi spiritualitas tokoh pendiri sekolah sebagai roh yang menggerakkan seluruh energi potensi warga sekolah; dan (3) citra yayasan pendiri dan pengelola sekolah yang memiliki komitmen menjaga Ideologi Pancasila dan UUD 1945 (Militer, Kodam V- Brawijaya, Malang).

Untuk mendukung peran kepemimpinan transformasional, kepala SMP Negeri Flores Barat, Indonesia Timur menerapkan pola pendekatan pengajaran budaya "lonto leok" masyarakat Manggarai. Alasan diterapkan pendekatan budaya lonto leok, karena seluruh warga sekolah (guru, pegawai, siswa, orang tua siswa, komite sekolah, masyarakat) sangat kuat dipengaruhi sistem nilai, norma, dan perilaku budaya lonto leok. Selain itu, penerapan pendekatan pengajaran budaya lonto leok mendukung salah satu konsep budaya yang dikembangkan oleh Hofstede (2001), yaitu dimensi individualisme-kolektivisme dalam bentuk pemberian penghargaan terhadap individu, dan solidaritas kerja tim. Penerapan dimensidimensipengajaranbudaya "lonto leok" yang dikembangkan oleh kepala sekolah dalam bentuk; (1) "tatong" (mendorong kemajuan dan perubahan) dengan memperluas dan meningkatkan kepentingan pengikut, menggerakkan pengikut untuk bekerja melampaui diri sendiri melalui visi bersama (Bass, 1997; Leithwood, Jantzi, \& Steinbach, 1999); (2) "toing" (mengajarkan cara mengatasi masalah), melalui stimulasi intektual untuk menemukan cara baru yang lebih inovatif dalam mengatasi masalah lama (Bass \& Avolio, 1994); (3) "toto nai bakok" (hati yang peduli) melalui tindakan peduli kepada kebutuhan bawahan (Bass, 1997; Bass \& Avolio, 1994; Leithwood, Jantzi, \& Steinbach, 1999; (4) "titong" (memberi tuntunan untuk berbuat sesuatu secara bertanggung jawab), dalam bentuk kerja yang profesional (Hofstede, 2001; Leithwood, Jantzi, \& Steinbach, 1999); dan (5) "tatang atau titing" (menguatkan dan memberdayakan) melalui motivasi 
inspirasional untuk mendorong bawahan melakukan lebih dari yang diharapkan; dan (6) bantang cama reje leleng (kerja sama), untuk mencapai tujuan bersama (Leithwood, Jantzi, \& Stainbach, 1999).

Di SMP Swasta Katolik, peran kepemimpinan transformasional kepala sekolah didukung melalui pendekatan humanistik. Yang melatarbelakangi penerapan pendekatan ini adalah keunggulan pribadi kepala sekolah sebagi seorang biarawati (integritas, keutuhan, keaslian diri) yang nampak dalam sikap keterbukaan, eksistensialisme dalam pengalaman baru, konsistensi, fleksibilitas, kreativitas, dan konstruktif (Rogers \& Freiberg, 1994) dan dorongan untuk menghidupkan kembali spiritualitas humanis tokoh pendiri kongregasi yang mengelola sekolah. Penghayatan spiritualitas humanis ini, diinspirasi oleh Suster Julie Billiart (Suster pendiri kongregasi) yaitu, "mencintai sesama manusia sebagai citra Allah". Bersumber dari Alkitab: "So God created mankind in his own image, in the image of God he created them; male and female he created them" (Genesis 1:27 New International Version). Nilai-nilai humanistik yang dikembangkan oleh kepala sekolah di lingkungan sekolah yaitu; semangat demokratis, solidaritas, kepekaan sosial, persaudaraan secara plural, toleransi, dialogis, penghargaan hak asasi, dan penghormatan terhadap kehidupan.

Aspek-aspekkeunggulan pribadi yang mendukung prinsip-prinsip pendekatan humanistik, mendukung pemikiran yang dikemukakan oleh Peus dan Frey (2009) yaitu: (1) pribadi yang terbuka, sehingga pengikut (guru dan pegawai) dapat menemukan makna dan visi sebagai pendidik, pengikut berhak atas transparansi melalui informasi dan komunikasi yang terbuka; (2) suportif, akomodatif, empati, lembut dan baik hati, semangat demokratis, solidaritas, kepekaan sosial, persaudaraan secara plural, toleransi, dialogis, penghargaan hak asasi, dan penghormatan terhadap kehidupan; (3) mendorong partisipasi dan otonomi di antara semua anggota tim kerja; (4) menegakkan rasa keadilan, cinta kasih, kebenaran, perdamaian, dan keutuhan ciptaan; (5) memberi umpan balik konstruktif; (6) bersama-sama mengembangkan tujuan dan pertumbuhan pribadi dan berfungsi sebagai model peran.

Di SMP Umum Nasional, peran kepemimpinan transformasional kepala sekolah didukung melalui pendekatan nasionalisme. Pendekatan nasionalisme diinspirasi oleh citra yayasan pendiri dan pengelola sekolah (Kodam V-Brawijaya), yang berkomitmen pada nilai historisitas lahirnya Negara Kesatuan Republik Indonesia yaitu; persatuan dalam keanekaragaman suku, agama, ras, dan golongan; ideologi Pancasila dan UUD 1945 (Mutrofin, 2007). Nilainilai historisitas lahirnya bangsa Indonesia mendukung prinsip-prinsip pendekatan nasionalisme dalam membangun visi bersama, sebagaimana yang dikemukakan dalam lima pilar Pancasila yaitu: keberagaman yang tolerant, kemanusiaan dalam membangun citra dan harga diri bangsa, kebudayaan dalam khazanah budaya nasional Indonesia, kegotongroyongan dalam karya anak bangsa, serta pemufakatan untuk menyatukan pikiran dan hati dalam menghadapi persaingan di era abad kreatif (The Ministry of Education and Culture, 2017).

Berdasarkan diskusi, ketiga kepala sekolah menerapkan pendekatan dalam peran kepemimpinan transformasional didasarkan pada kekayaan nilai-nilai yang terdapat di lingkungan sekolah. Nilai-nilai budaya merupakan nilai-nilai yang disepakati dan tertanam dalam lingkungan sekolah, yang mengakar pada nilai, kepercayaan, dan asumsi bawahan terhadap perilaku pemimpin (Hofstede, 2001; Sagala, 2008). Jika peri- 
laku atau reaksi pengikut memperkuat nilai-nilai, kepercayaan, dan asumsi pemimpin, maka ada kecocokan budaya, yang mengarah pada penerimaan dan efektivitas pemimpin (Sagala, 2008). Selain itu, pendekatan humanistik pemimpin didasarkan pada karakter diri dan spiritualitas humanis tokoh inspiratif. Pemimpin tidak hanya diidentifikasi oleh gaya kepemimpinan, tetapi juga oleh aspek kepribadian, yakni kesadaran tentang diri sendiri dan orang lain, dan apresiasi terhadap keragaman, fleksibilitas, dan paradoks. Sifat-sifat kepribadian pemimpin mempengaruhi kinerja pekerjaan dan memberikan cara yang efektif dan kuat dalam pengambilan keputusan (Blickle, Meurs, Wihler, et al., 2015; Haynes, Hitt, \& Campbell, 2015; Byrne, Silasi-Mansat, \& Worthy, 2015). Spiritualitas humanis yang dihidupkan di lingkungan sekolah merupakan bentuk perasaan kerja tertentu yang memberi energi aksi (roh yang menggerakan) (Dehler \& Welsh, 1994). Spiritualitas humanis ini merupakan spiritualitas di lingkungan kerja, bukan spiritualitas dalam sistem kepercayaan penuh (Sass, 2000). Spiritualitas di tempat kerja dapat digali dan dipelajari secara objektif ilmiah (Ashmos \& Duchon, 2000), dalam meningkatkan pem- belajaran organisasi, memadukan dan mengembangkan komunitas, melayani kebutuhan orang lain, membangun komitmen bersama dan mengekspresikan kasih sayang, kebijaksanaan, keharmonisan, dan menentang semua bentuk egosentris, sosiosentris, atau antroposentris. Selanjutnya, pendekatan nasionalisme pemimpin didasari komitmenyayasan pengelola sekolah untuk membangun karakter keindonesiaan yang toleran, menghargai keberagaman dalam bingkai Ideologi Pancasila dan Undang-Undang Dasar 1945 sebagai dasar negara (The Ministry of Education and Culture, 2017).

\section{Langkah-Langkah Peran Kepemimpinan Transformasional Kepala Sekolah Berba- sis Pendekatan Budaya Lonto Leok, Hu- manistik, dan Nasionalisme}

Dalam menerapkan program penguatan pendidikan karakter, ketiga kepala sekolah merujuk pada empat basis penguatan pendidikan karakter yang diarahkan oleh Kementerian Pendidikan dan Kebudayaan Indonesia, yaitu: kegiatan pengembangan diri, kegiatan kelas, kegiatan di lingkungan sekolah, kegiatan di lingkungan masyarakat (The Ministry of Education and Culture, 2017).

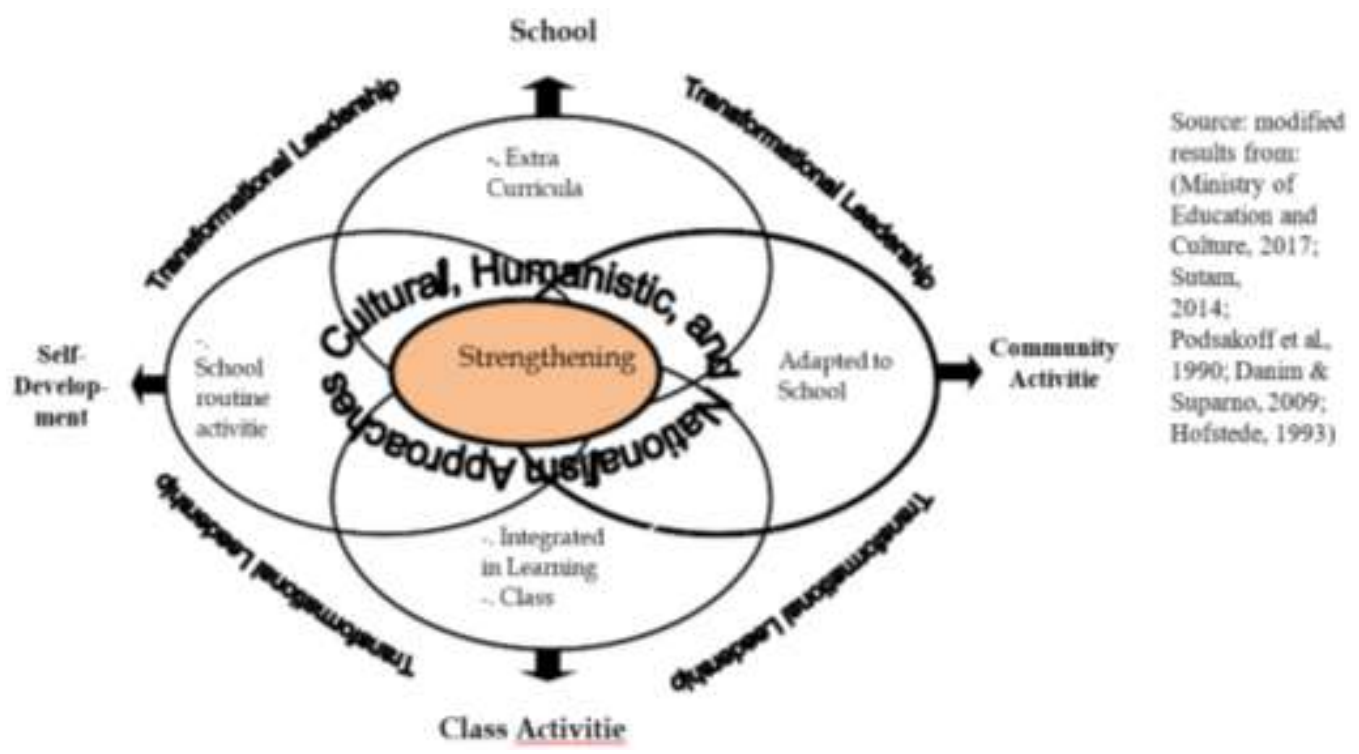

Gambar 2. Basis Penguatan Pendidikan Karakter di Sekolah 
Berdasarkan Gambar 2, langkah- langkah peran transformasional kepala sekolah melalui tiga pendekatan adalah sebagai berikut. Pertama, kegiatan pengembangan diri. Program ini dijalankan dalam berbagai bentuk kegiatan, seperti: (1) kegiatan rutin sekolah seperti; membersihkan kelas dan toilet, menanggung upacara bendera; (2) kegiatan spontan, seperti; tertib membuang sampah, tidak ribut di kelas, tidak melakukan kekerasan, berlaku sopan, tidak mencuri, berpakaian sopan; dan (3) keteladanan dalam berperilaku.

Langkah-langkah peran kepemimpinan transformasional kepala sekolah yang didukung melalui pendekatan budaya lonto leok, di SMP Negeri Flores Barat, Indonesia Timur, adalah sebagai berikut. (1) Mendorong seluruh komponen sekolah untuk bekerja sama. Pendekatan dimensi pengajaran lonto leok diterapkan dalam bentuk "bantang cama reje leleng" (partisipasi dalam kerja sama), seperti: mengajak guru, wali kelas untuk mendampingi siswa dalam kegiatan rutin sekolah; mengontrol siswa dalam kegiatan spontan. (2) Mendorong dan memberi motivasi inspiratif melalui pemberian kepercayaan kepada para guru untuk menemukan cara baru dalam mengarahkan perilaku siswa (Leithwood, Jantzi, \& Steinbach, 1999). Pendekatan dimensi pengajaran lonto leok dipraktikkan dalam bentuk "tatong" (mendorong kemajuan dan perubahan), seperti: guru memberi contoh perilaku yang baik; membimbing dan menangani masalah siswa dengan cinta dan perhatian; mengajak siswa untuk berperilaku moral yang baik di lingkungan sekolah dan masyarakat. Stimulasi intelektual diarahkan untuk memberdayakan kompetensi guru, terbuka menerima ide-ide baru, dan praktik-praktik baru untuk mengoptimalkan pertumbuhan dan perkembangan diri siswa (Bass \& Avolio, 1994).

Langkah-langkah peran kepemimpinan transformasional kepala sekolah melalui pendekatan humanistik di SMP Swasta Katolik, dilandasi oleh kesadaran bahwa manusia pada hakikatnya sempurna, dan membutuhkan aspirasi intrinsik untuk mengaktualisasikan diri (Maslow, 1987; Nemiroff, 1992). Hal ini ditunjukkan melalui langkah-langkah berikut. (1) Kerja sama dengan seluruh komponen sekolah untuk membimbing dan mengarahkan bersama perilaku siswa. (2) Membangun komitmen bersama untuk memberi contoh dalam berperilaku. (3) Menciptakan suasana keakraban dalam berkomunikasi. (4) Mengontrol diri, agar tidak mudah marah kepada guru, pegawai, dan siswa. (5) Mendampingi siswa yang bermasalah dengan penuh kasih sayang. Dalam konteks ini, kehadiran kepala sekolah lebih dekat dengan guru dan siswa (setara), dalam membangun komunikasi yang persuasif (Danim \& Suparno, 2009; Acevedo, 2012; Dierksmeier, 2016). Selain itu, pemberian stimulasi intelektual yang bernilai humanistikoleh kepala sekolah, terfokus pada; memahami seluruh komponen sekolah sebagai pribadi manusia, sehingga perlu untuk menghargai subjektivitas, relasionalitas, individualitas, dan kepribadian mereka, serta bertindak dengan tujuan untuk membangun komunitas bersama dan pertumbuhan manusia (kesejahteraan, aktualisasi diri) sebagai tujuan akhir (Aloni, 2011; Dierksmeier, 2016).

Kepala sekolah di SMP Umum Nasional, mendasarkan langkah-langkah transformatif-nasionalisme dalam kegiatan pengembangan diri siswa melalui pemberian motivasi inspiratif dan stimulasi intelektual untuk mengembangkan wawasan kebangsaan (Leithwood, Jantzi, \& Steinbach, 1999; The Ministry of Education and Culture, 
2016). Langkah-langkah praktis kepala sekolah dalam pengembangan wawasan kebangsaan dalam diri siswa, yaitu: (1) membangun kerja sama dengan guru, wali kelas untuk mewajibkan siswa mengikuti upacara bendera setiap hari senin; (2) mendorong piket harian dan wali kelas untuk mengontrol kegiatan spontan siswa; (3) membangun kerja sama sekolah dan orang tua untuk memberi teladan hidup toleran, menghargai dan mencintai sesama yang berbeda agama, hidup rukun dan damai dengan sesama (Koesoema, 2015). Dengan demikian, pemberian stimulasi intelektual yang berlandaskan nilai-nilai nasionalisme terarah pada dorongan untuk menghargai perbedaan; mencintai sesama tanpa memandang suku, agama, dan golongan; berkomunikasi yang terbuka dengan sesama warga bangsa Indonesia (Koesoema, 2010).

Meninjau pada diskusi yang ada, dijelaskan bahwa upaya pengembengan diri siswa dapat ditempuh melalui proses aktualisasi diri (Maslow, 1987). Aktualisasi diri dalam pemikiran Aristoteles mencakup aspek intelektual dan sosial. Dalam konsep penguatan pendidikan karakter, aspek intelektual dikembangkan melalui kegiatan pembelajaran berkarakter di kelas, di lingkungan sekolah dan masyarakat (Lickona, 2012; Koesoema, 2015). Sedangkan aspek sosial dikembangkan melalui peneladanan dan pembiasaan perilaku moral yang baik. Kedua aspek ini perlu dikembangkan secara optimal di sekolah melalui kerja sama sekolah, orang tua, dan masyarakat (Sagala, 2008; Daryanto, 2015). Dalam konteks ini, peran kepemimpinan transformasional kepala sekolah pada tiga sekolah, telah dilaksanakan secara optimal dengan menggunakan pola pendekatan yang berbeda, tetapi memiliki tujuan yang sama, yaitu eudamonia (kebahagian) diri, melalui hidup praktis (menghargai diri dan sama, disiplin, kerja sama, tanggung jawab, berperilaku etis) (Koesoema, 2015).

Kedua, kegiatan berbasis kelas. Langkah-langkah transformasional berbasis pendekatan budaya lonto leok oleh kepala sekolah di SMP Negeri Flores Barat, Indonesia Timur yaitu; (1) membangun visi bersama dan menjalankan tugas secara profesional serta bertanggung jawab, dengan memberi rangsangan pengetahuan kepada guru, agar dapat melakukan lebih dari yang seharusnya dilakukan; (2) mengoptimalkan program penguatan pendidikan karakter, kepala sekolah profesional dalam merancang pembelajaran berkarakter (mendesain perangkat, model, dan penilaian pembelajaran), serta memberdayakan para guru agar menjadi instruktur transformasional yang kompeten, sehingga ada kepuasan dan kepercayaan pada instruktur. Untuk memaksimalkan peran kepala sekolah, dimensi pengajaran lonto leok yang ditanamkan adalah "toing" (mengajarkan cara mengatasi masalah), dan "titong" (memberi tuntunan untuk berbuat sesuatu secara bertanggung jawab. Kedua dimensi pengajaran ini diimplementasikan dengan cara: (1) memberikan bimbingan teknis kepada guru, sehingga isi pembelajaran bernilai karakter; (2) memberikan ruang kebebasan, menumbuhkan optimisme, dan kreativitas kerja, sehingga bekerja tanpa diatur, kreatif dan inovasi; (3) memberi motivasi guru untuk menerjemahkan teori belajar, bekerja secara profesional untuk mencapai tujuan; (4) mendorong guru untuk menemani siswa dengan hati dan cinta; dan (5) mengembangkan perilaku moral yang konkrit di sekolah dan masyarakat (Leithwood, Jantzi, \& Steinbach, 1999).

Langkah-langkah transformasional berbasis pendekatan humanistik kepala sekolah di SMP Swasta Katolik, dalam bentuk: (1) bersama para guru, pegawai, komite 
sekolah, dan orang tua siswa, pengawas, merancang perangkat pembelajaran yang bermuatan karakter; (2) menawarkan kepada orang tua untuk mensheringkan pengetahuan praktis tentang kehidupan moral kepada siswa, dan waktunya dijadwalkan oleh pihak sekolah; (3) bersama guru bidang studi melakukan supervisi "persaudaraanpedagogis", dengan cara; (a) guru maupun kepala sekolah secara bergantian menyajikan sub pokok bahasan dari tema yang sama; (b) guru diminta untuk menyajikan seluruh materi, dan kepala sekolah bersama siswa membuat kesimpulan yang disertai penanaman nilai-nilai karakter, atau sebaliknya; (c) guru dan kepala sekolah bersama-sama menyajikan sub pokok bahasan, siswa diminta menyampaikan kesimpulan, disertai refleksi terhadap muatan nilai-nilai karakter yang terkandung dalam materi yang telah dibahas; (d) dalam menerapkan manajemen kelas, pendekatan humanistik kepala sekolah nampak dalam upaya membangun komitmen bersama yang diistilahkan "bona fide" artinya dengan tujuan baik dan bisa dipercaya. Maksudnya, dalam mengelola kelas, sikap guru harus terarah pada tujuan baik, dan guru harus bisa dipercaya oleh siswa. Hal ini ditunjukkan melalui sikap; mengajak siswa untuk menyimak pengajaran, menghargai pikiran teman, cara-cara yang etis dalam mengajukan pertanyaan, menciptakan lingkungan kelas yang nyaman, saling membelajarkan dengan sesama teman (tutor sebaya), mendampingi siswa dengan kasih.

Selain itu, dalam tindakan praktis pembelajaran, guru selaku fasilitator menerapkan model pembelajaran, sebagaiamana yang dikembangkan oleh Stiefel (1975); Gage \& Berliner (1991); Rogers \& Freiberg (1994) seperti berikut. (1) Membentuk karakter kemandirian siswa dalam belajar, dengan cara; mendesain model pembela- jaran yang tidak terstruktur, dan mengarahkan siswa untuk mengaturnya sesuai dengan konsep berpikir sendiri, membuat pilihan tugas untuk dikerjakan siswa, belajar bersama dan menggunakan pengetahuan siswa untuk menuntun teman lain, mendesain model pembelajaran yang berdasarkan masalah yang dikemukan oleh siswa. (2) Menggali karakteristik belajar siswa dengan mendorong siswa untuk menemukan sendiri nilai-nilai yang terkandung di dalam materi yang telah dikemukakan oleh siswa. (3) Membentuk karakter in-terpersonal, melalui pengondisian pembelajaran yang terbuka, merespons emosi siswa, mendorong minat melalui pengajuan pertanyaan untuk memenuhi rasa ingin tahu siswa, menghindari tekananmental. (4) Membentuk karakter komunikatif dalam diri, melalui dialog dan diskusi terbuka, menghargai pembicaraan siswa dalam mengungkapkan pikiran. (5) Membentuk karakter sosial, melalui pemberian tanggapan atau umpan balik dalam proses pembelajaran. (6) Mengondisikan ruang belajar dan desain pembelajaran yang memposisikan siswa sebagai sumber belajar, dan guru sebagai fasilitator. (7) Membentuk karakter keterampilan dalam belajar, dengan merancang berbagai desain pembelajaran yang aktif, kreatif, dan inovatif untuk dikembangkan oleh siswa sendiri.

Di SMP Umum Nasional, langkahlangkah transformasional berbasi pendekatan nasionalisme adalah sebagai berikut. (1) Melibatkan guru, orang tua siswa merancang perangkat pembelajaran berkarakter yang berisikan nilai-nilai kebangsaan. (2) Memberi motivasi inspiratif nilai-nilai kebangsaan kepada guru, sehingga dalam pembelajaran guru perlu mengikutsertakan penanaman nilai-nilai patriotisme dan cinta tanah air dalam pikiran siswa. (3) Memberi stimulasi intelektual kepada guru, agar 
dalam kegiatan pembelajaran diawali dengan menyanyikan lagu-lagu nasional, sehingga merangsang pikiran siswa untuk mencintai bangsa dan negara. (4) Memberikan dorongan kepada guru agar membiasakansiswa untuk hidup toleran, bekerja sama, saling membantu dalam setiap kegiatan pembelajaran. (5) Membangun komitmen bersama untuk mengondisikan lingkungan kelas yang berbineka tunggal ika, berideologi Pancasila, dan toleran. Dengan demikian, stimulasi intelektual yang diberikan kepala sekolah dalam kegiatan kelas seperti mengarahkan guru untuk memahami historisitas lahirnya negara dan bangsa, mendorong guru agar dalam kegiatan pembelajaran menerima dan membimbing siswa tanpa ada perbedaan, menghargai siswa dengan latar belakang yang berbeda, membangun semangat nasionalisme, patriotisme yang berakar pada lima sila Pancasila (Mutrofin, 2007; Koesoema, 2010; The Ministry of Education and Culture, 2017).

Berdasarkan diskusi yang ada, kegiatan kelas merupakan tempat pendidikan utama bagi praksis penguatan pendidikan karakter secara nyata di sekolah. Kelas menjadi komunitas belajar yang saling membutuhkan dan mengembangkan, baik secara akademik, moral, kepribadian, dan kerohanian. Dengan demikian, penguatan pendidikan karakter berbasis kelas dijalankan dengan cara membangun komunikasi yang persuasif dalam nuansa kekeluargaan, persaudaraan sehingga kepribadian siswa bertumbuh dan berkembang secaraa sehat, dewasa, dan bertanggung jawab. Hanya dengan mengembangkan lingkungan kelas yang ramah, penuh perhatian, corak relasional yang seimbang dan penuh penghargaan, karakter setiap individu bertumbuh dan berkembang secara efektif (Agboola \& Tsai, 2015). Semua corak relasional yang terjadi di dalam kelas harus diletakkan dalam kerangka pengembangan pembelajaran yang berkarakter.

Ketiga, berbasis budaya sekolah. Budaya sekolah yang positif menurut Anderman \& Maehr (1994) dikaitkan dengan: (1) motivasi dan prestasi siswa yang tinggi; (2) kolaborasi antar pemerintah; dan (3) perilaku guru. Untuk menciptakan budaya sekolah yang positif, langkah-langkah transformasional berbasis budaya lonto leok kepala sekolah di SMP Negeri Flores Barat, Indonesia Timur adalah (1) mengomunikasikan nilai-nilai karakter agar diketahui bersama oleh seluruh warga sekolah, orang tua dan masyarakat; (2) mendorong keteladanan dan kebiasaan perilaku guru; (3) mendorong komunikasi yang harmonis yang didasarkan pada nilai-nilai budaya kekeluargaan; dan (4) aturan sekolah bersifat fleksibel agar tidak dirasa menekan guru dan siswa. Langkah-langkah kepala sekolah ini memberi peluang yang besar kepada guru dan siswa untuk berkreasi menemukan cara baru menciptakan lingkungan sekolah yang berbudaya dan bermoral. Langkah-langkah ini didukung dengan penerapan dimensi pengajaran lonto leok, berupa; "toing" (mengajarkan cara mengatasi masalah), dan "bantang cama reje leleng" (kerja sama dalam membelajarkan siswa). Dalam konteks ini, lingkungan sekolah menjadi lingkungan pembelajaran karakter, tempat dimana siswa diterima dalam perbedaan pribadi yang unik, kehidupan yang toleran, saling menghormati dan menghargai dengan keunikan masing-masing (Sahenk, 2010).)

Selanjutnya, untuk membangun budaya sekolah yang positip di SMP Swasta Katolik, kepala sekolah memprogramkan berbagai jenis kegiatan ektrakurikuler, seperti; rekoleksi, retret, camping rohani, perayaan ekaristi, pengakuan dosa, menyediakan kantin kejujuran, membawakan koor di 
gereja, menggalang aksi solidaritas untuk membantu teman-teman yang lemah secara ekonomi, mengumpulkan uang untuk disumbangkan ke panti asuhan, menjalanakaan demokrasi pemilihan pengurus organisasi sekolah, membuka dialog keluarga dengan orang tua siswa, mencari donatur untuk membiayai siswa yang tidak mampu, bekerja sama dengan paguyupan alumni untuk membiayai siswa atau orang tua siswa yang sakit dan kekurangan biaya, memberi sumbangan kepada keluarga siswa atau guru yang meninggal, membentuk kelompok donor darah.

Nilai-nilai humanistik inilah yang membentuk budaya sekolah yang positip (Nemiroff, 1992; Koesoema, 2015; The Ministry of Education and Culture, 2017), selaras dengan inspirasi spiritualitas humanistik tokoh pendiri kongregasi yang mengelola sekolah, yaitu "mencintai sesama manusia sebagai citra Allah". Dalam mengoptimalkan program ini, langkah- langkah pendekatan humanistik yang diterapkan oleh kepala sekolah yaitu (1) melaksanakan rencana strategis sekolah untuk mengorganisasi kegiatan-kegiatan yang diprogramkan; (2) mendorong tim kerja bekerja sesuai dengan bidang tanggung jawab; (3) memupuk semangat kerja sama di antara tim kerja; (4) menciptakan komunikasi yang persuasif dengan semua pihak; (5) mendukung dan ikut terlibat dalam setiap pelaksanaan kegiatan; (6) menghidupkan dan menumbuhkan nilai-nilai keimanan; (7) membangun kepekaan diri untuk solider dan berpihak pada sesama yang berkekurangan; (8) menggalakkan semangat demokrasi untuk mencapai kesepakatan bersama; (9) mengundang para alumni untuk mendiskusikan tentang pengembangan sekolah, dan kondisi siswa; (10) memupuk nilai-nilai kejujuran; dan (11) mengadakan evaluasi bersama sesuai dengan kesepakatan ber- sama, untuk merefleksikan dan menginternalisasikan makna dari setiap kegiatan yang telah dilaksanakan.

Di SMP Umum Nasional, lingkungan sekolah dijadikan lingkungan yang kondusif untuk mempraktikkan pembelajaran cinta tanah air (nasionalis), kemandirian, dan gotong-royong. Pada tataran ini, lingkungan sekolah menjadi wadah penyemaian perilaku diri yang berkarakter. Penyemaian diri ini dijalankan melalui proses pembiasaan dan peneladanan seperti; menjalankan aturan secara disiplin, berpikir etis, menjunjung tinggi nilai-nilai moral, mengedepankan sikap setia, tanggung jawab, peduli, tahu mencintai budaya (tradisi dan bahasa), berkomitmen menjaga suasana toleransi demi kebersatuan dan keharmonisan hidup. Nasionalitas jiwa dan daya pikir ini diejahwantahkan dalam praksis hidup cinta budaya, taat hukum, jiwa berkorban demi kepentingan banyak orang, menghargai kebersatuan dan menghilangkan pemikiran primordialisme sempit, menjaga keutuhan dalam kebersatuan sehingga keberagaman dinilai sebagai mozaik yang indah dalam pandangan ke-Indonesia-an yang lebih toleran, terciptanya semangat demokrasi dan nasionalisme, bersilaturahim saat perayaan besar keagamaan; kantin kebinekaan-barokah (Koesoema, 2015; The Ministry of Education and Culture, 2017)

Berdasarkan diskusi yang ada, dalam konteks penguatan pendidikan karakter, kultur sekolah merupakan gambaran perilaku dan tindakan yang diciptakan melalui pengondian yang disepakati bersama di lingkungan sekolah. Dasar pola perilaku dan cara bertindak tersebut merupakan norma sosial, peraturan sekolah, dan kebijakan pendidikan di tingkat sekolah. Dengan kata lain, kultur sekolah dapat dikondisikan sebagai program internal sekolah yang berpengaruh efektif membentuk pola perilaku 
dan cara berpikir seluruh anggota komunitas sekolah (Koesoema, 2010; The Ministry of Education and Culture, 2017).

Keempat, berbasis lingkungan masyarakat. Pendidikan berbasis masyarakat merupakan model pendidikan yang mengikutsertakan masyarakat di dalam penyelenggaraan dan pengelolaan pendidikan. Kontribusi kepala sekolah di SMP Negeri Flores Barat, Indonesia Timur dalam membangun jejaring kerja sama di lingkungan masyarakat dilakukan dengan cara (1) interaksi dan dialog; (2) memberdayakan siswa dengan pengetahuan budaya melalui program "lutur lewe" (rumah bersama); (3) memberi wewenang kepada tim kerja, untuk menjalin komunikasi dengan tua golo (pemimpin adat) dalam kegiatan studi budaya; dan (4) membicarakan kegiatan kunjungan ke rumah adat (mbaru gendang) dan tinggal bersama masyarakat budaya (Bass \& Steidlmeier, 1999). Dimensi pengajaran lonto leok yang mengokohkan peran kepala sekolah, melalui "bantang cama reje leleng" (kerja sama). Melalui kerja sama, masyarakat mendukung program penguatan pendidikan karakter, dengan memberikan kesempatan kepada siswa untuk belajar dari lingkungan budaya, mendukung sekolah sebagai mitra dalam mengevaluasi program sekolah; berpartisipasi dalam pengambilan kebijakan sekolah.

Di SMP Swasta Katolik, diterapkan dalam berbagai bentuk berikut. (1) Kegiatan "ad infinitum" (sampai tak terhingga), maksudnya kegiatan pendidikan tidak hanya sebatas di lingkungan sekolah saja, tetapi berkelanjutan dengan pihak keluarga siswa melalui kegiatan kunjungan rumah. Kegiatan ini dijadwalkan setiap hari Minggu oleh pihak sekolah. (2) Membangun kepekaan sosial melalui kegiatan "amor vincit omnia" (cinta mengalahkan segalanya), dengan memberi beasiswa kepada siswa yang tidak mampu, dan gratis tinggal di asrama yang disiapkan sekolah. (3) Kerja sama dengan pihak kepolisian, melalui sosialisasi bahaya penggunaan narkoba, dan tertib lalu lintas. (4) Kerja sama dengan tenaga medis (dokter, bidan, perawat), untuk periksaan kesehatan. (5) Mengirim kartu ucapan setiap perayaan hari raya keagamaan. (6) Mengundang orang tua siswa untuk merayakan perayaan keagamaan di sekolah. (7) Mengundang tokoh-tokoh agama untuk memberi ceramah keagamaan. (8) Kegiatan bakti sosial di tempat-tempat umum. (9) Kegiatan Jumpa Berlian (Jumat Pertama Bersih Lingkungan).

Untuk mengoptimalkan program, langkah-langkah pendekatan humanistik kepala sekolah adalah (1) kerja sama dengan keluarga siswa dalam kegiatan pendampingan; (2) kerja sama antara sekolah dengan masyarakat untuk melindungi siswa dari bahaya narkoba, keamanan berlalulintas, dan kesehatan siswa; (3) menciptakan suasana toleran di lingkup sekolah, orang tua, dan masyarakat; (4) menyediakan beasiswa; (5) membangun kepedulian terhadap lingkungan alam; dan (6) memberi kebebasan untuk menghayati nilai-nilai keagamaan di sekolah.

Di SMP Umum Nasional dalam kegiatan di masyarakat, didasarkan pada etika moral bermasyarakat melalui kerja sama dengan keluarga siswa, alumni, pihak kepolisian, tim medis, tokoh agama (Koesoema, 2010; The Ministry of Education and Culture, 2017). Selain itu, mengondisikan perilaku siswa di tengah masyarakat, dengan selalu menunjukkan sikap cinta damai; menghargai persaudaraan dalam keberagaman suku, agama, bahasa, dan budaya; mencintai lingkungan; berlaku adil, dan kebiasaan berbuat amal baik (The Ministry of Education and Culture, 2010). Mengondisikan lingkungan sekolah sebagai wadah 
yang memberi keseimbangan karakter siswa, melalui kerja sama sekolah, orang tua, dan masyarakat (Shriner, Banev, Oxly, 2005). Dapat dikatakan, bahwa melalui pendekatan nasionalisme, kepala sekolah mengubah makna sekolah menjadi wadah pemberdayaan karakter siswa. Sekolah menjadi lingkunganyang kondusif untuk mempraktikkan pembelajaran mencinta, kemandirian, disiplin, berpikir etis, menjunjung tinggi nilai-nilai keberagaman dalam bingkai Negara Kesatuan Republik Indonesia (Koesoema, 2015; The Ministry of Education and Culture, 2017).

Berdasarkan diskusi, disadari bahwa kerja sama antara sekolah, keluarga, dan masyarakat perlu ditingkatkan supaya tidak terjadi kontradiksi atau ketidakselarasan (konflik) antara nilai-nilai yang harus dipegang teguh oleh siswa di sekolah dan yang harus diikuti di lingkungan keluarga dan masyarakt (Daryanto, 2015). Menciptakan suasana yang kondusif bagi penguatan pendidikan karakter siswa di sekolah, keluarga, dan masyarakat merupakan salah satu bentuk kemitraan moral yang perlu dikembangkan (The Ministry of Education and Culture, 2017).

\section{SIMPULAN}

Dalam terang penelitian terbaru, kelemahan peran kepala sekolah di Indonesia yang menyebabkan tidak optimalnya pelaksanaan penguatan pendidikan karakter di sekolah, telah ditemukan solusinya oleh tiga kepala sekolah melalui penerapan perilaku kepemimpinan transformasional dengan menggunakan pendekatan yang berbeda. Perbedaan penerapan pendekatan didasari beberapa alasan seperti berikut. (1) Seluruh komunitas sekolah (guru, pegawai, siswa, orang tua siswa, komite sekolah, masyarakat) di lingkungan SMP Negeri Flores Barat, Indonesia Timur sangat kuat dipe- ngaruhi sistem nilai, norma, dan perilaku budaya lonto leok. Didasarkan pada kondisi ini, maka kepala sekolah terdorong untuk menerapkan perilaku kepemimpinan transformasional dengan pola pendekatan dimensi pengajaran budaya lonto leok. (2) Dukungan keunggulan diri yang dimiliki oleh kepala sekolah yang adalah seorang biarawati kongregasi religius, dan dorongan untuk menghidupkan kembali spiritualitas humanis tokoh pendiri kongregasi yang mengelola sekolah, maka kepala sekolah di SMP Swasta Katolik terinspirasi untuk menerapkan model kepemimpinan transformasional melalui pendekatan humanistik. (3) Citra yayasan pengelola sekolah yang adalah Militer (Kodam V-Brawijaya-Malang), dengan komitmen menjaga ideologi Pancasila danUndang- Undang Dasar 1945, maka kepala sekolah di SMP Umum Nasional mendasarkan peran kepemimpinan transformasional berbasis pendekatan nasionalisme.

Ketiga model pendekatan tersebut dinilai sangat efektif dalam mendukung langkah-langkah peran kepemimpinan transformasional ketiga kepala sekolah. Selain itu, dan dalam konteks pelaksanaan penguatan pendidikan karakter di tiga sekolah yang diteliti, para kepala sekolah secara serius mengikuti panduan pelaksanaan penguatan pendidikan karakter yang ditetapkan oleh Kementerian Pendidikan dan Kebudayaan Republik Indonesia. Panduan praktis pelaksanaan penguatan pendidikan karakter mencakup kegiatan pengembangan diri, kegiatan kelas, kegiatan di lingkungan sekolah dan di lingkungan masyarakat. Keempat basis penguatan pendidikan karakter ini telah dilaksanakan secara efektif melalui langkahlangkah peran kepemimpinan transformasional kepala sekolah dengan didukung melalui pendekatan: (1) budaya lonto leok masyarakat Manggarai dalam bentuk "tatong" 
(mendorong kemajuan dan perubahan), "toing" (mengajarkan cara mengatasi masalah), "toto nai bakok" (hati yang peduli), "titong"(memberi tuntunan untuk berbuat sesuatu secara bertanggung jawab), "tatang atau titing" (menguatkan dan memberdayakan), "bantang cama reje leleng" (kerja sama); (2) humanistik, dengan penekanan pada; pribadi yang terbuka, suportif, akomodatif, empati, lembut dan baik hati, semangat demokratis, solidaritas, kepekaan sosial, persaudaraan secara plural, toleransi, dialogis, penghargaan hak asasi, dan penghormatan terhadap kehidupan; dan (3) nasionalisme, dengan penekanan pada keberagamaan yang tolerant, kemanusiaan dalam membangun citra dan harga diri bangsa, kebudayaan dalam khazanah budaya nasional Indonesian, kegotongroyongan dalam karya anak bangsa.

\section{UCAPAN TERIMA KASIH}

Dengan selesainya penelitian dan tulisan ini, penulis tidak lupa mengucapkan terima kasih kepada pihak-pihak yang telah membantu dalam penyelesian penelitian. Selanjutnya penulis mengucapkan terima kasih kepada ketua dewan redaksi Jurnal Pendidikan Karakter yang telah memproses artikel hingga layak dimuat di jurnal pada edisi sekarang ini.

\section{DAFTAR PUSTAKA}

Acevedo, A. (2011). Personalist business ethics and humanistic management: Insights from Jacques Maritain. Journal of Business Ethics, 105(2), 197-219. DOI:10.1007/s10551-011-0959-x.

Agboola, A., \& Tsai, K.C. (2015). Bring character education into classroom. European Journal of Educational Research, 1(2), 163-170. DOI: 10.12973/eu-jer.1.2.163.
Aloni, N. (2011). Humanistic education: From theory to practice. In W. Veugelers (Ed.). Education and Humanism: Linking Autonomy And Humanity (pp. 35-46). Rotterdam, Netherlands: Sense Publishers.

Anderman, E.M. \& Maehr, M.L. (1994). Motivation and schooling in the middle grades. Review of Educational Research, 64(2), 287-309. DOI: https://doi.org/10.3102/00346543064002287.

Ashmos, D.P., \& Duchon, D. (2000). Spirituality at work. Journal of Management Inquiry, 9(2), 134-145. DOI: https://doi.org/10.1177/10564926002008.

Bass, B.M. (1997). Does the transactionaltransformational leadership paradigm transcend organizational and national boundaries? Journal American Psychologist, 52 (2), 130-139. DOI: https://doi.org/10.1037/0003-066X.52.2.130.

Bass, B.M. \& Avolio, B.J. (1994). Improving organizational effectiveness through transformational leadership. Thousand Oaks, CA: Sage Publication.

Blickle, G., Meurs, J. A., Wihler, A., Ewen, C., Merkl, R., and Missfeld, T. (2015). Extraversion and job performance: How context relevance and bandwidth specificity create a non-linear, positive, and asymptotic relationship. Journal of Vocational Behavior, 87(1), 8088. DOI:10.1016/j.jvb.2014.12.009.

Byrne, K.A., Silasi-Mansat, C.D., \& Worthy, D.A. (2015). Who chokes under pressure? The big five personality traits and decision-making under pressure. Personality and Individual Differences, 74, 22-28. DOI: 10.1016/j.paid.2014.10.009 . 
Cook, L.A., Smith, W.S., Lan, W.Y., and Carpenter, D. (2016). The development of global competencies and global mindedness through global education experiences. International Journal of Global Education, 5(2) 1-15. Retrieved from https:// digitalcommons.csp.edu/cup_commons_faculty/27.

Creswell, J.W. (2009). Research design: Pendekatan kualitatif, kuantitatif, dan mixed. Yogyakarta: Pustaka Pelajar.

Danim, S., and Suparno. (2009). Transformational Leadership Management to School. Jakarta: Rineka Cipta.

Daryanto. (2015). Media pembelajaran. Bandung: PT. Sarana Tutorial Nurani Sejahtera.

Dehler, G.E., \& Welsh, M.A. (1994). Spirituality and organizational transformation: Implications for the new management paradigm. Journal of Managerial Psychology, 9(6), 17-26. DOI: http://dx.doi.org/10.1108/02683949 410070179.

Denzin, N. \& Lincoln, Y. (2000). The discipline and practice of qualitative research. In: Denzin, N.K. \& Lincoln, Y.S., Eds., Handbook of Qualitative Research, Thousand Oaks, CA: Sage Publication (pp. 1-32).

Dierksmeier, C. (2016). What is 'Humanistic' About Humanistic Management? Humanist Management Journal, 1, 9-32. DOI: $10.1007 /$ s41463-016-0002-6.

Endah, S. (2012). Implementation of the character education curriculum. Yogyakarta: Citra Aji Parama.

Gage, N., and Berliner, D. (1991). Educational psychology (5th ed.). Boston: Houghton, Mifflin.

Haynes, K.T., Hitt, M.A., \& Campbell, J.T. (2015). The dark side of leadership: toward a midrange theory of hubris and greed in entrepreneurial contexts. Journal of Management Studies, 52(4), 479-505. DOI: 10.1111/joms.12127.

Hofstede, G.H. (2001). Culture's consequences: Comparing values, behaviors, institutions and organizations across nations. Behaviour Research and Therapy, 41(7). DOI: 10.1016/S0005-7967 (02)00184-5.

Holy Bible. (2011). Genesis 1:27 New International Version (NIV). by Biblica, Inc. Retrieved from https://www.biblegateway.com/passage/ ?search= Genesis, accessed on July 20, 2019.

Holy Bible. (2011). John 15:4 New International Version (NIV). by Biblica, Inc. Retrieved from https://www.biblegateway.com/passage/?search=John, accessed on July 20, 2019.

Kleden, I. (1987). Sikap ilmiah dan kritik kebudayaan. Jakarta: LP3ES.

Koesoema, D.A. (2010). Character education: Strategies to educate children in the global age. Jakarta: Grasindo.

Koesoema, D. A. (2015). Character education strategy, mental revolution in educational institutions. Yogyakarta: Kanisius.

Leithwood, K., Jantzi, D. \& Steinbach, R. (1999). Changing leadership for changing times. Philadelphia: Open University Press.

Lickona, T. (2012). Education for character: 
Mendidik untuk membentuk karakter. Jakarta: PT Bumi Aksara.

Lovvorn, A.S. \& Chen, J.S. (2011). Developing a global mindset: The relationship between an international assignment and cultural intelligence. International Journal of Business and Social Science, 2(9), 275-283. Retrieved from https://www.researchgate.net/publicatio n/268062864_Developing_a_Global_ Mindset_The_Relationship_between_ an_International_Assignment_and_C ultural_Intelligence.

Maslow, A. (1987). Motivation and personality - 3rd ed. New York: Harper and Row.

Melé, D. (2016). Understanding humanistic management. Humanistic Management Journal, 1(1), 33-55. DOI: 10.1007/ s41463-016-0011-5.

Miles, M.B., Huberman, A.M., \& Saldana, J. (2014). Qualitative data analysis, a methods sourcebook, $3^{\text {rd }}$ edition. Thousand Oaks, CA: Sage Publications.

Mutrofin (2007). Autocritical education; evaluative ideas. Yogyakarta: LaksBang PRESSindo.

Nemiroff, G.H. (1992). Reconstructing education: Toward a pedagogy of critical humanism. New York, NY: Bergin \& Garvey.

Peraturan Presiden Republik Indonesia Nomor 87 Tahun 2017 tentang Penguatan Pendidikan Karakter.

Peus, C. \& Frey, D. (2009). Humanism at work: Crucial organizational cultures and leadership principles. In H. Spitzeck, M. Pirson, W. Amann, S. Khan, \& E. Von Kimakowitz, Humanism in
Business (pp. 260-277). Cambridge: Cambridge University Press.

Rogers, C., \& Freiberg, H. J. (1994). Freedom to learn (3rd ed.). New York: Macmillan/Merrill.

Sagala, S. (2008). Konsep dan makna pembelajaran. Bandung: Alfabeta.

Sahenk, S. S. (2010). Characteristics of the headmasters, teachers, and students in an effective school. Innovation and Creativity in Education, 2(2), 4298-4304. DOI: 10.1016/j.sbspro.2010.03.682.

Sass, J.S. (2000). Characterizing organizational spirituality: An organizational communication culture approach. Communication Studies, 51(3), 195-207. DOI: $10.1080 / 10510970009388520$.

Shriner, P., Banev, S., and Oxly, S. (2005). Holistic education resource book. Verlage: Waxmann.

Stiefel, R.T. (1975). Towards a more humanistic approach in management education. Management Education and Development, 6(3), 156-165.

The Ministry of Education and Culture. (2010). Development of national culture and character education. Jakarta: Secretariat of the Curriculum Research and Development Center.

The Ministry of Education and Culture. (2016). Guidelines for strengthening character education. Jakarta: Secretariat Team for Strengthening Character Education.

The Ministry of Education and Culture. (2017). Strengthening character education; training module for principals. 
Jakarta: Secretariat Team Strengthening Character Education

Veugelers, W. (2007). Creating critical- democratic citizenship education: empowering humanity and democracy in dutch education. Compare, 37(1), 105119. DOI: https://doi.org/10.1080/03057920601061893.

Waddock, S. (2016). Developing humanistic leadership education. Humanistic Management Journal, 1(1), 57-73. DOI: 10.1007/s41463-016-0003-5. Management Journal, 1, 57-73. DOI 10.1007/s41463-016-0003-5.
Yin, R.K. (2017). Case study research and applications: Design and methods. New York: Sage Publication.

Zamroni, (2011). Pendidikan demokrasi pada masyarakat multikultural. Yogyakarta: Gavin Kalam Utama. 